\title{
SPC-P1: a pathogenicity-associated prophage of Salmonella paratyphi C
}

\author{
Qing-Hua Zou' ${ }^{1 \dagger}$, Qing-Hai Li ${ }^{2,6 \dagger}$, Hong-Yun Zhu' ${ }^{1}$, Ye Feng ${ }^{2,6}$, Yong-Guo Li ${ }^{3}$, Randal N Johnston ${ }^{4}$, Gui-Rong Liu ${ }^{2,6^{*}}$, \\ Shu-Lin Liu ${ }^{1,2,3,5,6^{*}}$
}

\begin{abstract}
Background: Salmonella paratyphi C is one of the few human-adapted pathogens along with S. typhi, S. paratyphi A and S. paratyphi B that cause typhoid, but it is not clear whether these bacteria cause the disease by the same or different pathogenic mechanisms. Notably, these typhoid agents have distinct sets of large genomic insertions, which may encode different pathogenicity factors. Previously we identified a novel prophage, SPC-P1, in S. paratyphi C RKS4594 and wondered whether it might be involved in pathogenicity of the bacteria.

Results: We analyzed the sequence of SPC-P1 and found that it is an inducible phage with an overall G+C content of $47.24 \%$, similar to that of most Salmonella phages such as P22 and ST64T but significantly lower than the $52.16 \%$ average of the RKS4594 chromosome. Electron microscopy showed short-tailed phage particles very similar to the lambdoid phage CUS-3. To evaluate its roles in pathogenicity, we lysogenized S. paratyphi C strain CN13/87, which did not have this prophage, and infected mice with the lysogenized CN13/87. Compared to the phage-free wild type CN13/87, the lysogenized CN13/87 exhibited significantly increased virulence and caused multi-organ damages in mice at considerably lower infection doses.
\end{abstract}

Conclusions: SPC-P1 contributes pathogenicity to S. paratyphi C in animal infection models, so it is possible that this prophage is involved in typhoid pathogenesis in humans. Genetic and functional analyses of SPC-P1 may facilitate the study of pathogenic evolution of the extant typhoid agents, providing particular help in elucidating the pathogenic determinants of the typhoid agents.

\section{Background}

The bacterial genus Salmonella contains more than 2600 very closely related serovars, classified by the Kauffmann-White Scheme according to their differences in the somatic $(\mathrm{O})$ and flagellar $(\mathrm{H})$ antigens $[1,2]$. Although essentially all Salmonella bacteria are pathogens, they may have different host ranges or cause different diseases.

Over 1400 Salmonella serovars may infect humans, with most of them causing self-limiting gastroenteritis. On the other hand, a few Salmonella serovars, such as Salmonella typhi, S. paratyphi A, S. paratyphi B and

\footnotetext{
* Correspondence: grliu.natsumi@gmail.com; slliu@ucalgary.ca † Contributed equally

'Department of Microbiology, Peking University Health Science Center, Beijing, PR China

${ }^{2}$ Genomics Research Center (one of The State-Province Key Laboratories of Biomedicine-Pharmaceutics of China), Harbin Medical University, Harbin, PR China

Full list of author information is available at the end of the article
}

S. paratyphi $\mathrm{C}$, are adapted to humans and cause typhoid fever, a serious and potentially fatal systemic infection [3]. It is not clear whether these Salmonella typhoid agents use the same, similar or totally different pathogenic traits to infect the same host and cause the disease. Genomic comparisons between S. typhi and $S$. paratyphi A did not reveal a common genetic basis possibly responsible for human adaptation or typhoid pathogenesis $[4,5]$. Notably, various Salmonella pathogenicity islands (SPIs) or prophages have been identified in the Salmonella typhoid agents, e.g., SPI-7 in S. typhi $[6,7]$ and S. paratyphi C [8], and SPA-1, SPA-2 and SPA-3 in S. paratyphi A [4], but their specific roles in typhoid pathogenesis have not been well established.

In a previous study, we located several insertions in the genome of S. paratyphi C strain RKS4594 by comparing it with other Salmonella genomes [9], including one, SPC$\mathrm{P} 1$, which was a prophage present only in S. paratyphi C among all sequenced Salmonella strains [8]. In this study,
C Biomed Central

C 2010 Zou et al; licensee BioMed Central Ltd. This is an Open Access article distributed under the terms of the Creative Commons Attribution License (http://creativecommons.org/licenses/by/2.0), which permits unrestricted use, distribution, and reproduction in any medium, provided the original work is properly cited. 
we characterized this novel prophage, predicted its possible roles in the pathogenicity of S. paratyphi $\mathrm{C}$, and evaluated its potential contributions to pathogenicity in animal experiments. We found that, although no previously known pathogenicity-associated genes were identified in the prophage, SPC-P1 did increase the pathogenicity of the bacteria.

\section{Results}

Genomic location and identification of prophage SPC-P1 We screened the complete nucleotide sequence of the $S$. paratyphi C RKS4594 genome (CP000857) by Phage_Finder http://phage-finder.sourceforge.net for possible prophage sequences and located five regions with typical prophage characteristics, with four of them having been reported in other Salmonella serovars and well studied previously, including Gifsy-1 and Gifsy-2 in S. typhimurium LT2 [10] and SPA-1 and Phage SPA-3-P2 in S. paratyphi A ATCC9150 [4]. These prophages have also been known to be present in several other Salmonella serovars, such as S. choleraesuis [11]. The remaining genomic region corresponds to the previously mapped $39 \mathrm{~kb}$ insertion between genes purC and purF [9] and has typical features of a prophage; here we designate this region SPC-P1. Sequence analysis showed that SPC$\mathrm{P} 1$ lies between two adjacent genes, $p g t E$ and $y f d C$, in $S$. paratyphi C RKS4594, whereas in fifteen other published Salmonella genomes (see their accession numbers below), we did not find DNA insertions in this region. The ends of SPC-P1 were set by two direct repeats of the sequence tggtgtcccctgcag, a typical feature for the ends of prophage DNA sequences. One of the repeat sequences begins at 109 bp upstream of SPC-P1 ORF1, and the other begins at $165 \mathrm{bp}$ downstream of ORF53 and continues with an arg tRNA gene. The total length of SPC-P1 is 39,659 bp and the overall G+C content is $47.24 \%$, which is similar to those of phage P22 (47.1\%) [12,13] and ST64T (47.5\%) [14] and is significantly lower than the $52.16 \%$ average of the S. paratyphi C RKS4594 chromosome.

\section{Layout and predicted products of SPC-P1 genes}

Using Vector NTI 9.0 and GLIMMER3, we identified 53 ORFs in SPC-P1, designated consecutively from ORF1 through ORF53 (Additional file 1 Table S1), with the ORF encoding the terminase small unit as ORF1. As shown in Additional file 1 Table S1, the G+C contents of individual ORFs vary from $31.65 \%$ (ORF 16) to $53.89 \%$ (ORF 48), demonstrating an obvious mosaic structure.

Of the 53 ORFs, 47 had ATG and six (ORF13, ORF16, ORF21, ORF29, ORF31, ORF44) had GTG as the start codon. Functions of the SPC-P1genes were inferred based on similarities with characterized genes from other phages; some salient features of these proteinencoding genes are summarized in Additional file 1 Table S1.

Three of the predicted SPC-P1 protein-encoding genes (ORF16, ORF24, and ORF45) have no phage-borne homologues in the current databases. However, it is worthwhile to note that the deduced product of ORF16 shows a low but significant level of similarity with the acyltransferase 3 of Pseudomonas syringae py. Syringae B728a (Additional file 1 Table S1). On the other hand, several bacteriophages such as Shigella flexneri bacteriophage Sf6 have O-antigen acetyltransferase gene in their genomes. As the protein products of such genes may alter the bacterial O-antigens [15], they likely would make important contributions to the bacterial virulence. The remaining 50 ORFs all have close homologues with previously characterized phages of enteric bacteria. The ORFs can be divided into nine main clusters according to the predicted functions, which are arranged in the following order: Head, Tail, Integration, Ea region, Recombination, Immunity, Replication, Nin region and Lysis (Figure 1). The gene cluster encoding the phage head covers a large region and consists of twelve ORFs. This region is closely related to the morphogenetic regions of previously characterized phages such as CUS-3, HK620, Sf6, P22, ST104 and ST64, however none of the latter six phages has the whole set of twelve ORFs seen in SPC-P1 (CUS-3, the most closely related phage, has the first eleven ORFs but only part of the twelfth ORF; Figure 1). The arrangement of the ORFs in this part of SPC-P1 is similar to that of CUS-3, Sf6 or HK620 in the gene order of 5'-small terminaselarge terminase-portal-decoration-coat-3'. This suggests that ORF1-ORF12 define a type of head gene module, which is highly conservative in these phages (See more details in Additional file 1 Table S1). The gene cluster encoding phage tail is composed of only one ORF, ORF15, the deduced product of which shows certain similarities to those of some known phages, such as P22, ST104, ST64T, HK620, CUS-3 and Sf6. Additionally, SPC-P1 also contains gene clusters for phage integration (ORF17-18), recombination (ORF26-32), immunity (ORF33-38), replication (ORF39-41) and lysis (ORF50-53), suggesting that SPC-P1 encodes all functions required by and sufficient for an active phage.

\section{Phylogenetic analysis of SPC-P1}

Both nucleotide and deduced protein sequence homologies indicate that SPC-P1 is a member of the lambdoid phage group and the predicted functions of the genes are similar to those of lambdoid phages, especially to CUS-3, HK620, Sf6, ST64T, P22 and ST104. Each of these phages has about half of their deduced protein products showing high similarity with those of SPC-P1, 


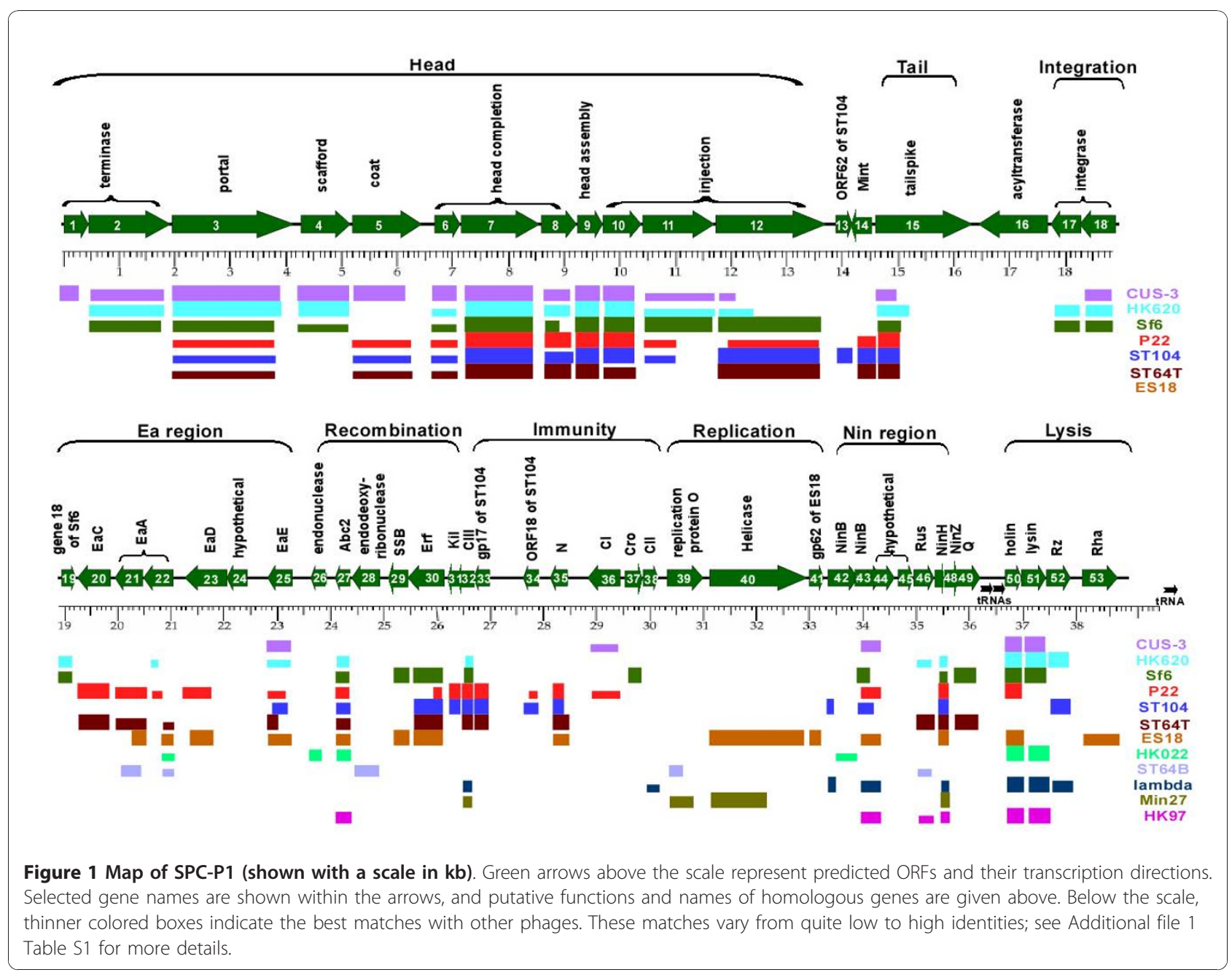

providing evidence of mosaic architecture and extensive recombination events creating SPC-P1 during evolution. We chose twelve phages for comparisons with SPC-P1 using Mauve 2.3.1, which can produce a phylogenetic tree of mosaic phage and prophage genomes. The phylogenetic tree thus obtained revealed that SPC-P1 is closest to CUS-3 (Figure 2).

\section{Distribution of SPC-P1 in other Salmonella serovars and among S. paratyphi $\mathrm{C}$ strains}

To determine whether SPC-P1 is present in other Salmonella serovars, we searched the GenBank Nucleotide collection (nr/nt) database and found that only some segments of SPC-P1 could be found in S. choleraesuis SC-B67 and S. paratyphi A ATCC9150. We then searched other wild type strains of $S$. paratyphi $\mathrm{C}$ for SPC-P1. Using primers amplifying six segments of SPCP1 with overlapping regions (Table 1), we amplified regions of 407 to $7282 \mathrm{bp}, 7217$ to $13126 \mathrm{bp}, 12813$ to $19040 \mathrm{bp}, 18726$ to $25764 \mathrm{bp}, 25409$ to $32079 \mathrm{bp}$ and

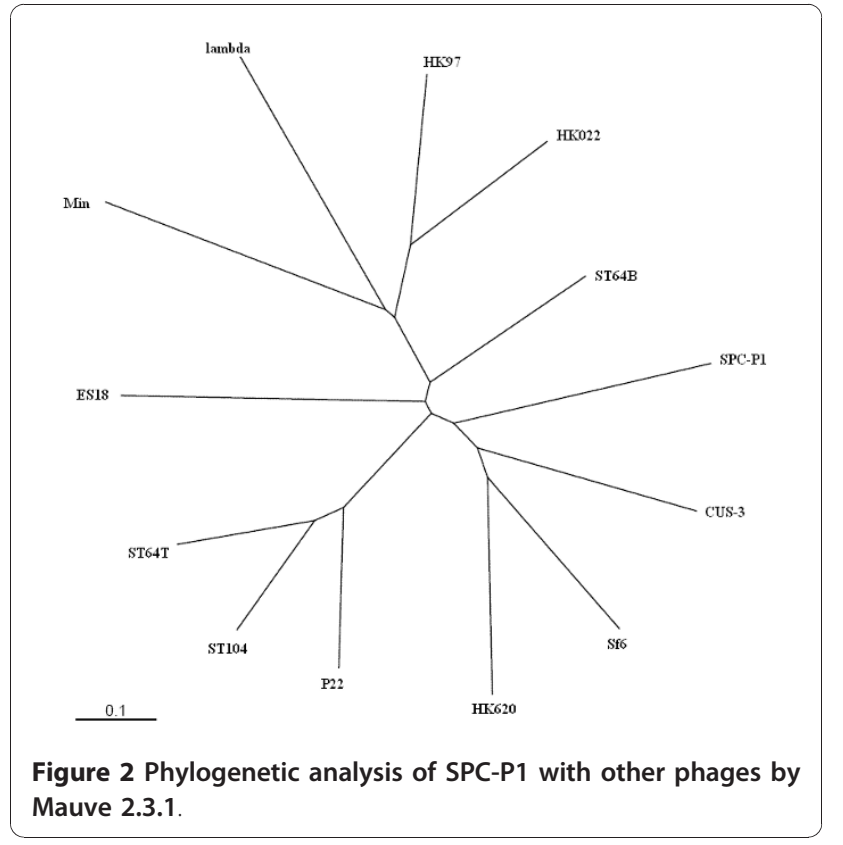


Table 1 Primers used for amplification of SPC-P1

\begin{tabular}{|c|c|c|c|}
\hline primers & sequences & Site at SPC-P1 & Product size (bp) \\
\hline $1 \mathrm{~s}$ & 5'TTACTCCGCTGTTTCTTCTTCGTCTTCTIT 3' & 407 & 6876 \\
\hline $1 \mathrm{r}$ & 5'GGGATGGTGTGGGCTATGGTGCTTGCTTATGT 3' & 7282 & \\
\hline $2 \mathrm{~s}$ & 5'ATCGTCTAGGCGTTTCATGATTGCTCTGTTCGTG 3' & 7217 & 5910 \\
\hline $2 r$ & 5'GTTATGGTATTCAAACTCAATCCACTGTTGCTTA 3' & 13126 & \\
\hline $3 s$ & :5'GCGGCAAGGTGTGGAATGGAGAGCGAGAACTGGA 3' & 12813 & 6228 \\
\hline $3 r$ & 5'ATTTCCTTTGACGAGCACCCGACCACCATTATC 3' & 19040 & \\
\hline $4 \mathrm{~s}$ & 5'GGAACGGTCAGAGAGATTGAGGTATGAGCAGAGT 3' & 18726 & 7039 \\
\hline $4 r$ & 5'TTTGGCATGATTCTGGCCTTCGATTCGATACGT 3' & 25764 & \\
\hline $5 \mathrm{~s}$ & 5'AGCAACGCATGGCTAAGTGGGCAGAGGATAACGG 3' & 25409 & 6671 \\
\hline $5 r$ & 5'TTAGCCGCATCAGAGCCAGGAACTGTCGGAAACG 3' & 32079 & \\
\hline $6 \mathrm{~s}$ & 5'TCCGCAGCAATCAGGCAGGAGAAGCACTAACAGC 3' & 31704 & 6731 \\
\hline $6 r$ & 5'ATGCAGCTGGCACACGTAAGCGGCGGGAC 3' & 38434 & \\
\hline
\end{tabular}

31704 to 38434 bp, respectively (Figure 3), and demonstrated that the whole sequence of SPC-P1 is also present in eight of the fourteen wild type strains tested (Table 2).

\section{Induction of SPC-P1 and morphological analysis}

Since SPC-P1 seems to contain all necessary genes for a viable phage, we wondered whether it could be induced from the bacterial genome. Upon mitomycin $\mathrm{C}$ treatment, the culture of $S$. paratyphi C RKS4594 became clearer than the culture without mitomycin treatment, suggesting that phage were induced to lyse the cells.

For propagation and characterization of the induced phage, we attempted finding a strain of S. paratyphi C that is sensitive to the phage. We used the lysate of RKS4594 after mitomycin C treatment to infect the seven $S$. paratyphi C strains, whose PCR results were negative for SPC-P1 (Table 2) and inspected plaque formation on them. We found plaques on strain CN13/87. To confirm that the plaques were formed by SPC-P1, we carried out PCR identification on the plaques; all six segments of SPC-P1 were amplified by PCR with the six pairs of primers (Figure 4 lanes 13-18).

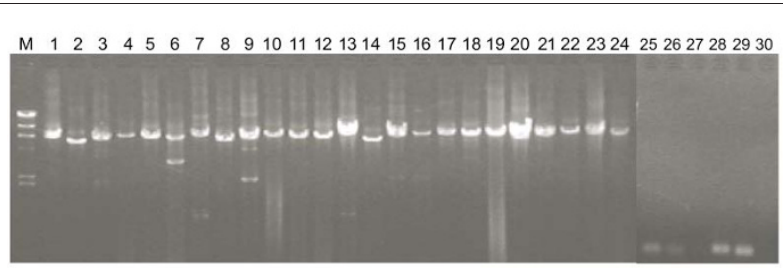

Figure 3 Representative PCR results of SPC-P1 in S. paratyphi C strains. Lanes: $M, \lambda$ DNA/Hindlll marker; $1-6$, the six fragments of SPC-P1 in strain RKS4585; 7-12, the six fragments of SPC-P1 in strain RKS4586; 13-18, the six fragments of SPC-P1 in strain RKS4588; 1924 , the six fragments of SPC-P1 in strain RKS4594; 25-30, the results of $\mathrm{CN13/87}$, which is negative for SPC-P1.
Based on its genomic organization, we predicted that SPC-P1 phage would resemble CUS-3 with a characteristic short tail. To validate its morphology, we singleplaque isolated SPC-P1 and propagated the phage on CN13/87 for transmission electron microscopy. We saw typical short-tailed phage particles (Figure 5).

\section{Lysogenic conversion of CN13/87 by SPC-P1}

Since SPC-P1 could be induced from the genome of $S$. paratyphi C RKS4594 and strain $\mathrm{CN13/87}$ is sensitive to SPC-P1, we wondered whether SPC-P1 could lysogenize CN13/87. SPC-P1 and CN13/87 were mixed at a multiplicity of infection of 1:100 and then co-cultured on LB plates. Single colonies were isolated and infected with SPC-P1 again. Three of the eight colonies, No. 3, 4 and 8 on the plate shown in Figure 6, were resistant to SPC$\mathrm{P} 1$, suggesting lysogenization by, and immunity to, SPCP1. We amplified all six segments of SPC-P1 from them,

Table 2 PCR detection of SPC-P1 in S. paratyphi C strains

\begin{tabular}{ccc}
\hline Strain No. & SGSC No. & PCR results \\
\hline RKS4587 & 2289 & - \\
RKS4620 & 2291 & - \\
33 KK & 2419 & - \\
CN13/87 & 2712 & - \\
RKS4585 & 2998 & + \\
RKS4586 & 2999 & + \\
RKS4588 & 3000 & - \\
RKS4589 & 3001 & + \\
RKS4590 & 3002 & + \\
RKS4591 & 3003 & + \\
RKS4592 & 3004 & + \\
RKS4593 & 3005 & - \\
RKS4595 & 3006 & + \\
RKS4596 & 3007 & - \\
\hline
\end{tabular}

"+"means the strain is positive for SPC-P1 and "-" means the strain is negative for SPC-P1. 


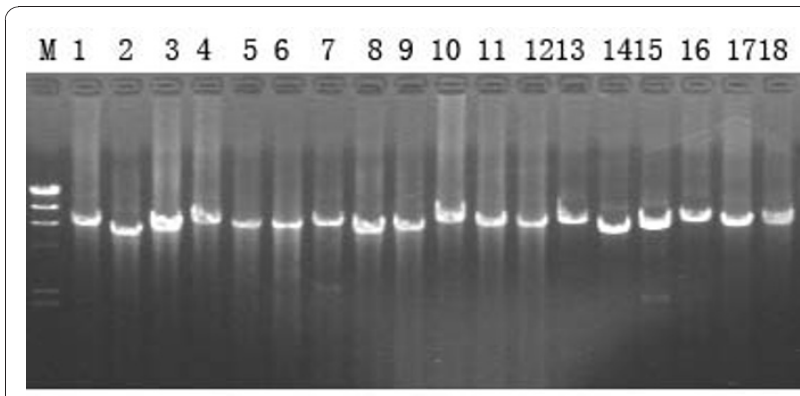

Figure 4 PCR results of a plaque and two randomly picked CN13/87 colonies with SPC-P1 lysogenization. Lanes: $M, \lambda$ DNA/ Hind III marker; $1-6$, the six fragments of SPC-P1 in the genome of colony No.3; 7-12, the six fragments of SPC-P1 in the genome of colony No.4; 13-18, the six fragments of SPC-P1 in one plaque.

demonstrating lysogenization of the bacteria by SPC-P1; representative results are shown in Figure 4.

\section{Increased pathogenicity of lysogenized $\mathrm{CN} 13 / 87$ in mouse infection experiments}

Since ORF16 shows certain sequence similarity with the acyltransferase 3 of Pseudomonas syringae py. Syringae $\mathrm{B} 728 \mathrm{a}$ and the $\mathrm{O}$-antigen genes play important roles in bacterial virulence, we wondered whether SPC-P1 might be involved in pathogenicity of the bacteria. We orally infected mice with $10^{4}, 10^{5}, 10^{6}, 10^{7}, 10^{8}$ or $10^{9}$ viable bacterial cells (colony forming units, cfu) of wild type or lysogenized CN13/87. We did not include the S. paratyphi C strain RKS4594, from which SPC-P1 was originally isolated, because we did not have a SPC-P1-free RKS4594 so comparison of virulence between SPC-P1plus and SPC-P1-minus RKS4594 lines was not possible. On day 7 after infection, we sacrificed the mice and cultured homogenized liver, lung and spleen tissues to detect bacteria and determine the numbers of bacterial cells that will be required to establish infection in half of the inoculated mice (i.e., median infective dose, $\mathrm{ID}_{50}$ ). The wild type and lysogenized CN13/87 strains demonstrated greatly different pathogenicity on the animals, with $\mathrm{ID}_{50}$ values of $2.14 \times 10^{7} \mathrm{cfus}$ and $6.76 \times 10^{4} \mathrm{cfus}$,

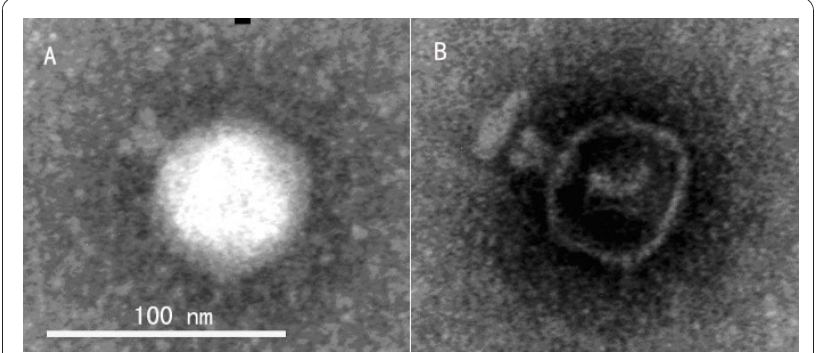

Figure 5 SPC-P1 particle shown by transmission electron microscopy. A, a phage particle with the head and short tail clearly seen; $B$, an empty phage head with a short tail connected to it.

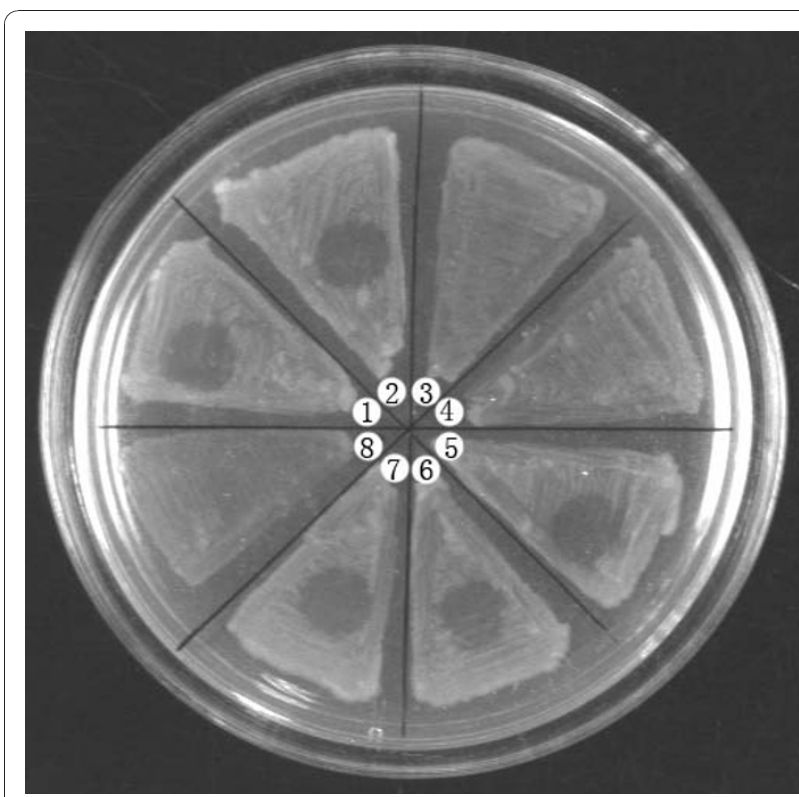

Figure 6 Lysis resistance of lysogenized CN13/87 against SPC-P1. Colonies: No. 1, S. paratyphi C CN13/87 wild type strain as the SPC-P1 negative control; No. 3, 4 and 8, lysogenized CN13/87 that are resistant to SPC-P1 lysis (SPC-P1 lysogenization confirmed by P(R); No. 2, 5-7, survivors of CN13/87 after SPC-P1 infection without lysogenization by the phage.

respectively (Table 3). All recovered bacteria were confirmed to be identical to those in the inocula by serological and phage tests and pulsed field gel electrophoresis (data not shown). Pathological examinations showed multiple organ damages in mice infected with $10^{9}$ cells of lysogenized CN13/87 (Figure 7).

\section{Discussion}

Bacteria evolve by accumulating mutations and incorporating laterally transferred genes, among which phages are by far the most important driving force. For example, since the divergence from E. coli about 120-160 million years ago [16-18], Salmonella have developed into a great number of distinct lineages, with more than 2600

Table 3 Infection ${ }^{a}$ of mice at different doses of bacteria

\begin{tabular}{cccc}
\hline Group & Dose (cfu) & \multicolumn{2}{c}{ No. infected mice (\%) } \\
\cline { 2 - 4 } & & Lysogenized CN13/87 & Wild type CN13/87 \\
\hline 1 & 0 & $1 / 6(17 \%)$ & 0 \\
\hline 2 & $1 \times 10^{4}$ & $4 / 6(67 \%)$ & 0 \\
\hline 3 & $1 \times 10^{5}$ & $5 / 6(83 \%)$ & 0 \\
\hline 4 & $1 \times 10^{6}$ & $6 / 6(100 \%)$ & $2 / 6(17 \%)$ \\
\hline 5 & $1 \times 10^{7}$ & $6 / 6(100 \%)$ & $4 / 6(67 \%)$ \\
\hline 6 & $1 \times 10^{8}$ & $6 / 6(100 \%)$ & $6 / 6(100 \%)$ \\
\hline 7 & $1 \times 10^{9}$ &
\end{tabular}

${ }^{a}$ Infection means appearance of bacteria in any of the examined organ tissues of the animal. 


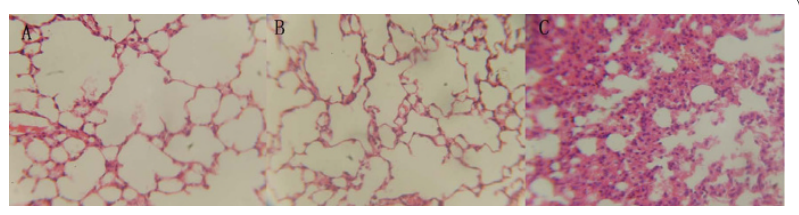

Figure 7 Tissue damage of mice associated with SPC-P1lysonenized CN13/87 infection. Lung sections of mice orally inoculated with water (A), wild type CN13/87 at $10^{9} \mathrm{cfu} / 0.5 \mathrm{ml}$ (B) and SPC-P1-lysonenized CN13/87 at $10^{9} \mathrm{cfu} / 0.5 \mathrm{ml}$ (C). No significant differences were seen between (A) and (B), but inflammation cell infiltration and tissue damages are obvious in (C).

serovars currently recognized [2]. They all share a core genome, which is about $90 \%$ of the genes for Salmonella subgroup I serovars, with the remaining ca. $10 \%$ genes being specific to individual serovars [19]. Genomic analyses reveal that Salmonella harbor numerous temperate bacteriophages [13,20-23]. In fact, most of the non-core genome sequences are derived from phages, which play key roles in bacterial genome evolution and pathogenicity. In this study, we characterized a novel prophage, SPC-P1, in the genome of S. paratyphi C RKS4594 and demonstrated that this phage is present only in S. paratyphi C strains but not in any other Salmonella serovars tested. SPC-P1 exhibits typical characteristics of prophages, including a significantly lower overall $\mathrm{G}+\mathrm{C}$ content than that of the bacterial genome average, repeat sequences at the ends of its genome, and tRNA genes at the integration site. Sequence analysis showed that SPCP1 has a substantial portion of its genome being highly related to previously characterized lambdoid phages and it has a complete set of genes to encode a viable phage. The mitomycin $\mathrm{C}$ induction test confirmed this.

Although prophages are widely found in bacterial genomes, most of them are defective, unable to produce viable phage particles. Sequence analysis indicated close relatedness of SPC-P1 to CUS-3 and electron microscopy also revealed morphological similarity between SPC-P1 and CUS-3. Like CUS-3, SPC-P1 also has a cosahedral head and a short tail. Since SPC-P1 could be induced from the bacterial genome and we had available the SPC-P1 sensitive strain CN13/87, we had the opportunity to propagate this phage for further studies. SPCP1 could not only lyse CN13/87 but also lysogenize it, which allows us to study the possible roles of SPC-P1 in bacterial pathogenicity.

S. paratyphi $\mathrm{C}$ is one of the few Salmonella serovars that cause typhoid fever in humans, along with S. typhi, S. paratyphi A and S. paratyphi B, but it is not fully clear whether different Salmonella typhoid agents cause the disease by similar or distinct mechanisms. Prophages can contribute important biological properties to their bacterial hosts and analysis of the prophages may shed light on the evolution of their hosts. Considering that the human-adapted typhoid agents may have evolved by convergent processes [8], we speculate that $S$. paratyphi $\mathrm{C}$ may cause the disease by different mechanisms than those used by other Salmonella typhoid agents. As SPCP1 is found only in S. paratyphi C, it may be involved in the pathogenesis of typhoid caused by S. paratyphi C. Taking the advantage that $S$. paratyphi $\mathrm{C}$, unlike other human-adapted Salmonella typhoid agents, can infect hosts other than humans if large inocula are used $[24,25]$, we compared pathogenicity of $S$. paratyphi C between SPC-P1-free and SPC-P1-lysogenized isogenic strains. We found that SPC-P1 significantly increased the pathogenicity of $S$. paratyphi $\mathrm{C}$ and caused multiple organ damages in the animals (see Table 3 and Figure 7), but the molecular basis is yet to be understood.

\section{Conclusions}

SPC-P1 contributes pathogenicity to $S$. paratyphi C in animal infection models, so it is possible that this prophage is involved in typhoid pathogenesis in humans. Genetic and functional analyses of SPC-P1 may facilitate the study of evolution of the different typhoid agents, providing particular help in elucidating the pathogenic determinants of the typhoid agents.

\section{Methods}

\section{Bacterial strains and growth conditions}

Bacterial strains used in this study are listed in Table 2 and detailed information on them can be obtained from the Salmonella Genetic Stock Center http://www.ucalgary.ca/ kesander. Bacteria were grown overnight at $37^{\circ}$ $\mathrm{C}$ with shaking in LB broth.

\section{Genome Sequencing}

The genome sequence of RKS4594 was obtained from several pUC18 genomic shotgun libraries using dye terminator chemistry on Megabace1000 and ABI3730 automated sequencers as described previously [8].

\section{ORF prediction and homology search}

Open reading frames (ORF) of SPC-P1 were predicted by Vector NTI and Glimmer 3. Products of ORFs were deduced based on homologies to known proteins by the BLASTP server of NCBI. Similarity of nucleotide sequence between SPC-P1 and the other completely sequenced Salmonella prophages was evaluated by the BLASTN server of NCBI.

\section{$\mathrm{G}+\mathrm{C}$ content analysis and tRNA prediction}

The $\mathrm{G}+\mathrm{C}$ content of each predicted ORF was analyzed using the DNAstar software. tRNA was predicted using tRNAscan-SE software http://lowelab.ucsc.edu/ tRNAscan-SE/. 
Distribution of SPC-P1 in other S. paratyphi C strains Genomic DNA of $S$. paratyphi $C$ strains was isolated by the Genomic DNA Extraction Kit (TIANZE, China). LA taq polymerases were purchased from Takara. PCR reactions were performed as follows: $94^{\circ} \mathrm{C}, 1 \mathrm{~min} ; 98^{\circ} \mathrm{C}$, 20 sec; $68^{\circ} \mathrm{C}, 10 \mathrm{~min}, 30$ cycles; $72^{\circ} \mathrm{C}, 10 \mathrm{~min}$.

\section{Induction of SPC-P1}

S. paratyphi C RKS4594 was grown in LB medium at $37^{\circ} \mathrm{C}$ for $4 \mathrm{~h}$, followed by addition of four times volume of fresh LB. At this point, mitomycin $\mathrm{C}$ was added to a final concentration of $0.5 \mu / \mathrm{ml}$. The cultures were shaken, $120 \mathrm{r} / \mathrm{min}$, at $37^{\circ} \mathrm{C}$ for $14 \mathrm{~h}$. Chloroform was added to a final concentration of $1 \%$ to the culture, followed by vortex of the culture for $1 \mathrm{~min}$. Cell debris was removed by centrifugation at $12000 \mathrm{rpm}$ for $10 \mathrm{~min}$. The supernatant containing SPC-P1 was preserved at $4^{\circ} \mathrm{C}$ until use.

\section{Plaque formation test}

S. paratyphi C strain $\mathrm{CN} 13 / 87$ did not harbor SPC-P1 and so was used as a recipient in the test. Ten-fold serial dilutions of the bacterial lysate were made. Then $10 \mu \mathrm{l}$ of a dilution and $100 \mu \mathrm{l}$ of $\mathrm{CN} 13 / 87$ fresh culture $(4 \mathrm{~h})$ were mixed and incubated at $37^{\circ} \mathrm{C}$ for $20 \mathrm{~min}$ before addition of $3 \mathrm{ml} \mathrm{0.7 \%} \mathrm{LB}$ agar cooled to about $45^{\circ} \mathrm{C}$. After mixing quickly, the $0.7 \%$ LB agar containing the lysate and bacteria was spread to a $1.5 \%$ LB agar plate, which then was cultured overnight. For identification, phage in individual plaques were picked up and propagated on CN13/87 before DNA was extracted for further PCR analysis and for transmission electron microscopy.

\section{Lysogenization of strain $\mathrm{CN} 13 / 87$}

$\mathrm{CN} 13 / 87$ was cultured at $37^{\circ} \mathrm{C}$ in $2 \mathrm{ml} \mathrm{LB}$ for $4 \mathrm{~h}$. Then $10 \mu \mathrm{l} \mathrm{SPC}-\mathrm{P} 1\left(10^{8} \mathrm{pfu} / \mathrm{ml}\right)$ was added and the culture was continued at $37^{\circ} \mathrm{C}$ overnight. Serial 10 -fold dilutions of the culture were spread onto LB agar plates and incubated overnight at $37^{\circ} \mathrm{C}$. Single colonies were picked up and spread uniformly onto fresh LB plates, eight colonies per plate. A small drop of SPC-P1 (about $5 \mu \mathrm{l}$ ) was placed onto the bacterial patches. The plates were cultured overnight before inspection of SPC-P1 plaques on the bacteria.

\section{Animal infection experiments}

Female BALB/c mice, 6-8 weeks old, were divided into seven groups, twelve mice per group with six inoculated with wild type CN13/87 and six with SPC-P1-lysogenized CN13/87 orally with $0.5 \mathrm{ml}$ sterile water containing no bacteria (group 1), $10^{4} \mathrm{cfu} / 0.5 \mathrm{ml}$ (group 2), $10^{5} \mathrm{cfu} /$ $0.5 \mathrm{ml}$ (group 3), $10^{6} \mathrm{cfu} / 0.5 \mathrm{ml}$ (group 4), $10^{7} \mathrm{cfu} / 0.5$ $\mathrm{ml}$ (group 5), $10^{8} \mathrm{cfu} / 0.5 \mathrm{ml}$ (group 6) or $10^{9} \mathrm{cfu} / 0.5 \mathrm{ml}$ (group 7). When the mice were sacrificed as specified, liver, lung and spleen tissues were taken for bacterial detection and histological examinations. ID50 was determined as described [26].

\section{Accession numbers}

Genbank: S. typhimurium LT2 [NC_003197]; S. choleraesuis [SC-B67 NC_006905]; S. paratyphi A ATCC9150 [NC_006511]; S. typhi CT18 [NC_003198]; S. typhi Ty2 [NC_004631]; S. paratyphi C RKS4594 [CP000857]; S. schwarzengrund CVM19633 [NC_011094]; S. paratyphi A AKU_12601 [NC_011147]; S. newport SL254 [NC_011080]; S. heidelberg SL476 [NC_011083]; S. gallinarum 287/91 [NC_011274]; S. enteritidis P125109 [NC_011294]; S. dublin CT_02021853 [NC_011205]; S. agona SL483 [NC_011149]; S. arizonae 62:z4,z23:[NC_010067]; Enterobacteria phage ES18 [NC_006949]; Enterobacteria phage ST64T [NC_004348]; Enterobacteria phage ST104 [AB102868]; Enterobacteria phage CUS-3 [CP000711]; Enterobacteria phage HK620 [NC_002730]; Enterobacteria phage Sf6 [NC_005344]; Enterobacteria phage HK022[NC_002166]; Enterobacteria phage HK97 [NC_002167]; Enterobacteria phage lambda [NC_001416]; Bacteriophage P22[AF217253]; Salmonella typhimurium phage ST64B [AY055382]; Enterobacteria phage Min27 [NC_010237].

\section{Additional material}

Additional file 1: The ORFs in SPC-P1 DNA whose putative products exhibit significant homology to extant protein sequences. This file includes the position of each ORFs in the chromosome of RKS4594, the start and stop codon, the size, $\% \mathrm{G}+\mathrm{C}$, homology proteins and the $\%$ Identity range, E-value of each ORFs.

\section{Acknowledgements}

This work was supported by a grant of Canadian Institutes of Health Research to RNJ; a National Natural Science Foundation of China (NSFC30970078) and a grant of Natural Science Foundation of Heilongjiang Province of China to GRL; a grant from Harbin Medical University, grants of National Natural Science Foundation of China (NSFC30870098, 30970119, 81030029), a Specialized Research Fund for the Doctoral Program of Higher Education (SRFDP, 20092307110001), and a 985 Project grant of Peking University Health Science Center to SLL.

\section{Author details}

${ }^{1}$ Department of Microbiology, Peking University Health Science Center, Beijing, PR China. ${ }^{2}$ Genomics Research Center (one of The State-Province Key Laboratories of Biomedicine-Pharmaceutics of China), Harbin Medical University, Harbin, PR China. ${ }^{3}$ Genetic Detection Center of First Hospital, Harbin Medical University, Harbin, PR China. ${ }^{4}$ Department of Biochemistry and Molecular Biology, University of Calgary, Calgary, Canada. ${ }^{5}$ Department of Microbiology and Infectious Diseases, University of Calgary, Calgary, Canada. ${ }^{6}$ Systemomics Research Center, School of Pharmacy, Harbin Medical University, Harbin, PR China.

\section{Authors' contributions}

$\mathrm{QHZ}$ initiated the project and carried out the bioinformatic analysis; $\mathrm{QHL}$ carried out animal experiments and determined $\mathrm{ID}_{50}$ of the bacteria on mice; QHZ and HYZ did phage induction, morphologic examination, 
lysogenization and PFGE experiments; YF was involved in bioinformatic analysis; YGL contributed reagents; RNJ, GRL and SLL coordinated the work; $\mathrm{QHZ}$ and SLL produced the manuscript. All authors read and approved the final manuscript.

Received: 27 January 2010 Accepted: 30 December 2010

Published: 30 December 2010

\section{References}

1. Kauffmann F, Edwards PR: A revised, simplified Kauffmann-White schema. Acta Pathol Microbiol Scand 1957, 41(3):242-246.

2. Popoff MY, Bockemuhl J, Gheesling LL: Supplement 2002 (no. 46) to the Kauffmann-White scheme. Res Microbiol 2004, 155(7):568-570.

3. Parry CM, Hien TT, Dougan G, White NJ, Farrar JJ: Typhoid fever. N Engl J Med 2002, 347(22):1770-1782

4. McClelland M, Sanderson KE, Clifton SW, Latreille P, Porwollik S, Sabo A, Meyer R, Bieri T, Ozersky P, McLellan M, et al: Comparison of genome degradation in Paratyphi A and Typhi, human-restricted serovars of Salmonella enterica that cause typhoid. Nat Genet 2004, 36(12):1268-1274.

5. Didelot X, Achtman M, Parkhill J, Thomson NR, Falush D: A bimodal pattern of relatedness between the Salmonella Paratyphi A and Typhi genomes: convergence or divergence by homologous recombination? Genome Res 2007, 17(1):61-68.

6. Parkhill J, Dougan G, James KD, Thomson NR, Pickard D, Wain J, Churcher C, Mungall KL, Bentley SD, Holden MT, et al: Complete genome sequence of a multiple drug resistant Salmonella enterica serovar Typhi CT18. Nature 2001, 413(6858):848-852.

7. Deng W, Liou SR, Plunkett G, Mayhew GF, Rose DJ, Burland V, Kodoyianni V, Schwartz DC, Blattner FR: Comparative genomics of Salmonella enterica serovar Typhi strains Ty2 and CT18. J Bacteriol 2003, 185(7):2330-2337.

8. Liu WQ, Feng Y, Wang Y, Zou QH, Chen F, Guo JT, Peng YH, Jin Y, Li YG, Hu SN, et al: Salmonella paratyphi C: genetic divergence from Salmonella choleraesuis and pathogenic convergence with Salmonella typhi. PLOS ONE 2009, 4(2):e4510.

9. Liu WQ, Liu GR, Li JQ, Xu GM, Qi D, He XY, Deng J, Zhang FM, Johnston RN, Liu SL: Diverse genome structures of Salmonella paratyphi C. BMC Genomics 2007, 8.

10. McClelland M, Sanderson KE, Spieth J, Clifton SW, Latreille P, Courtney L, Porwollik S, Ali J, Dante M, Du F, et al: Complete genome sequence of Salmonella enterica serovar Typhimurium LT2. Nature 2001, 413(6858):852-856.

11. Chiu CH, Tang P, Chu C, Hu S, Bao Q, Yu J, Chou YY, Wang HS, Lee YS: The genome sequence of Salmonella enterica serovar Choleraesuis, a highly invasive and resistant zoonotic pathogen. Nucleic Acids Res 2005, 33(5):1690-1698.

12. Pedulla ML, Ford ME, Karthikeyan T, Houtz JM, Hendrix RW, Hatfull GF, Poteete AR, Gilcrease EB, Winn-Stapley DA, Casjens SR: Corrected sequence of the bacteriophage p22 genome. Journal of bacteriology 2003, 185(4):1475-1477.

13. Schicklmaier $\mathrm{P}$, Wieland $\mathrm{T}$, Schmieger $\mathrm{H}$ : Molecular characterization and module composition of P22-related Salmonella phage genomes. J Biotechnol 1999, 73(2-3):185-194.

14. Mmolawa PT, Schmieger H, Heuzenroeder MW: Bacteriophage ST64B, genetic mosaic of genes from diverse sources isolated from Salmonella enterica serovar typhimurium DT 64. J Bacteriol 2003, 185(21):6481-6485.

15. Gemski P, Koeltzow DE, Formal SB: Phage conversion of Shigella flexneri group antigens. Infection and immunity 1975, 11(4):685-691.

16. Ochman H, Wilson AC: Evolution in bacteria: evidence for a universal substitution rate in cellular genomes. J Mol Evol 1987, 26(1-2):74-86.

17. Doolittle RF, Feng DF, Tsang S, Cho G, Little E: Determining divergence times of the major kingdoms of living organisms with a protein clock. Science 1996, 271(5248):470-477.

18. Feng DF, Cho G, Doolittle RF: Determining divergence times with a protein clock: update and reevaluation. Proc Natl Acad Sci USA 1997 94(24):13028-13033.

19. Feng Y, Liu WQ, Sanderson KE, Liu SL: Comparison of Salmonella genomes. In Salmonella: From Genome to Function. Edited by: Porwollik S. Caister Academic Press; 2011:49-67.

20. Casjens S: Prophages and bacterial genomics: what have we learned so far? Mol Microbiol 2003, 49(2):277-300.
21. Casjens SR, Gilcrease EB, Winn-Stapley DA, Schicklmaier P, Schmieger $H$, Pedulla ML, Ford ME, Houtz JM, Hatfull GF, Hendrix RW: The generalized transducing Salmonella bacteriophage ES18: complete genome sequence and DNA packaging strategy. J Bacteriol 2005, 187(3):1091-1104.

22. Mmolawa PT, Schmieger H, Tucker CP, Heuzenroeder MW: Genomic structure of the Salmonella enterica serovar Typhimurium DT 64 bacteriophage ST64T: evidence for modular genetic architecture. J Bacteriol 2003, 185(11):3473-3475.

23. Tanaka K, Nishimori K, Makino S, Nishimori T, Kanno T, Ishihara R, Sameshima T, Akiba M, Nakazawa M, Yokomizo Y, et al: Molecular characterization of a prophage of Salmonella enterica serotype Typhimurium DT104. J Clin Microbiol 2004, 42(4):1807-1812.

24. Archer GT, Whitby JL: Protection of mice by living Vi and $O$ vaccines against death caused by Salmonella paratyphi C. J Hyg (Lond) 1957, 55(4):513-526.

25. Howard JG: Resistance to infection with Salmonella paratyphi C in mice parasitized with a relatively avirulent strain of Salmonella typhimurium. Nature 1961, 191:87-88.

26. Reed $\sqcup$, Muench $\mathrm{H}$ : A simple method of estimating fifty percent endpoints. The American Journal of Hygiene 1938, 27:493-497.

doi:10.1186/1471-2164-11-729

Cite this article as: Zou et al: SPC-P1: a pathogenicity-associated prophage of Salmonella paratyphi C. BMC Genomics 2010 11:729.

\section{Submit your next manuscript to BioMed Central and take full advantage of:}

- Convenient online submission

- Thorough peer review

- No space constraints or color figure charges

- Immediate publication on acceptance

- Inclusion in PubMed, CAS, Scopus and Google Scholar

- Research which is freely available for redistribution

Submit your manuscript at www.biomedcentral.com/submit
Biomed Central 